\title{
The Future Triumph of Medical Science Over Cancer: a mural for oncology
}

$\mathrm{T}$

he first half of the 20th-century saw the birth of the Mexican muralist movement, which, in the post-revolutionary period, was primarily concerned with exalting the great social, technical and scientific movements that were taking place in Mexico and elsewhere in the world. One of the areas that caught the muralists' interest and admiration was medicine. To them, health was an innate right of the human race, thus it had to be available to the general population, just like art and culture. ${ }^{1}$

The artists rejected canvas and chose the large, open and public spaces of walls to deliver their images to the public. Many of Mexico's greatest murals are located in health institutions. The National Institute of Cardiology, the La Raza Hospital, the central offices of the Institute of Social Security, the National Institute of Pediatrics and the National Medical Center all had their walls decorated by the frescoes of Diego Rivera, David Alfaro Siqueiros, Juan O'Gorman, José Chávez Morado,
Jorge Gonzàlez Camarena and many others. Social security was an important step toward making health care accessible to everyone and the muralists were enthusiastic about celebrating this through their paintings on the walls of these newly built hospitals. ${ }^{1,2}$

The Institute of Social Security's National Medical Center, built in 1963, is a large compound comprising several hospitals and clinics. Among them is the Oncology Hospital, one of Mexico's leading oncological health care centres. It was designed to be the flagship hospital for the Institute of Social Security and its creation had a profound social impact in that it provided free, high quality health care. The decoration of the lobby of this building was commissioned to Siqueiros, an accomplished muralist and fervent follower of communism. Siqueiros was one of Mexico's greatest painters, alongside Rivera and José Clemente Orozco, and his oil paintings and murals can be found in the country's most important museums and public institu- tions, including the main building of Mexico's National Autonomous University. At the Institute of Social Security Oncology Hospital, Siqueiros painted The Future Triumph of Medical Science Over Cancer, a 26-metrelong mural painted in acrylic on wooden panels that highlights the social implications of medicine and its responsibility to the people - one of the underlying principles of Institute of Social Security at that time. ${ }^{3}$

In the mural, a large assembly of people advances toward a group of doctors, dressed in surgical gowns, located at the centre of the mural. The people are raising their hands in a demand for health. The body of a naked woman rests on a linear particle accelerator, from which a beam of energy seems to shoot toward 2 grotesque creatures that represent cancer. The crowd surrounding the monsters seems to cheer as the ray of science hits the dreadful personifications of disease and death. The focal point of the mural is the handshake between the medical profession and the people, represented

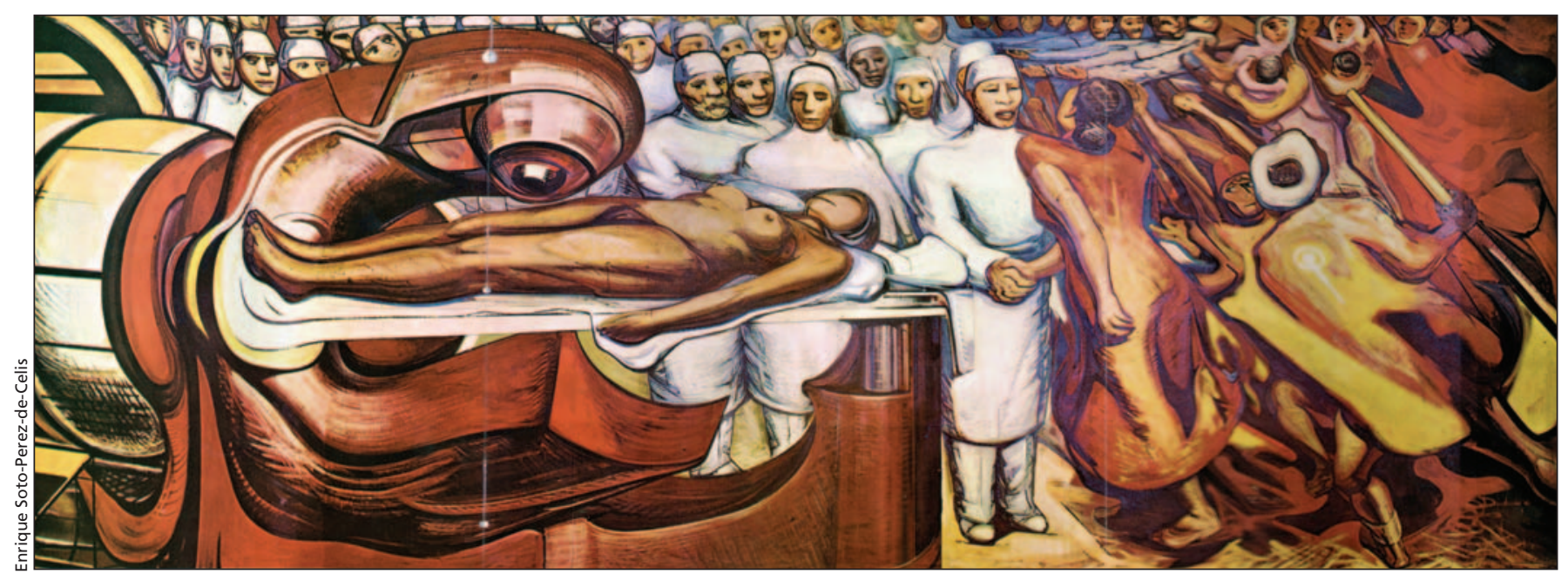

David Alfaro Siqueiros, The Future Triumph of Medical Science over Cancer (1958). Acrylic over wooden panels. $26 \times 2.45 \mathrm{~m}$. A detail from the mural at the Institute of Social Security Oncology Hospital, Mexico City, Mexico. 
by the doctor and the woman. The mural symbolizes the power of medicine as one of the main driving forces behind the well-being of the country and the hope it

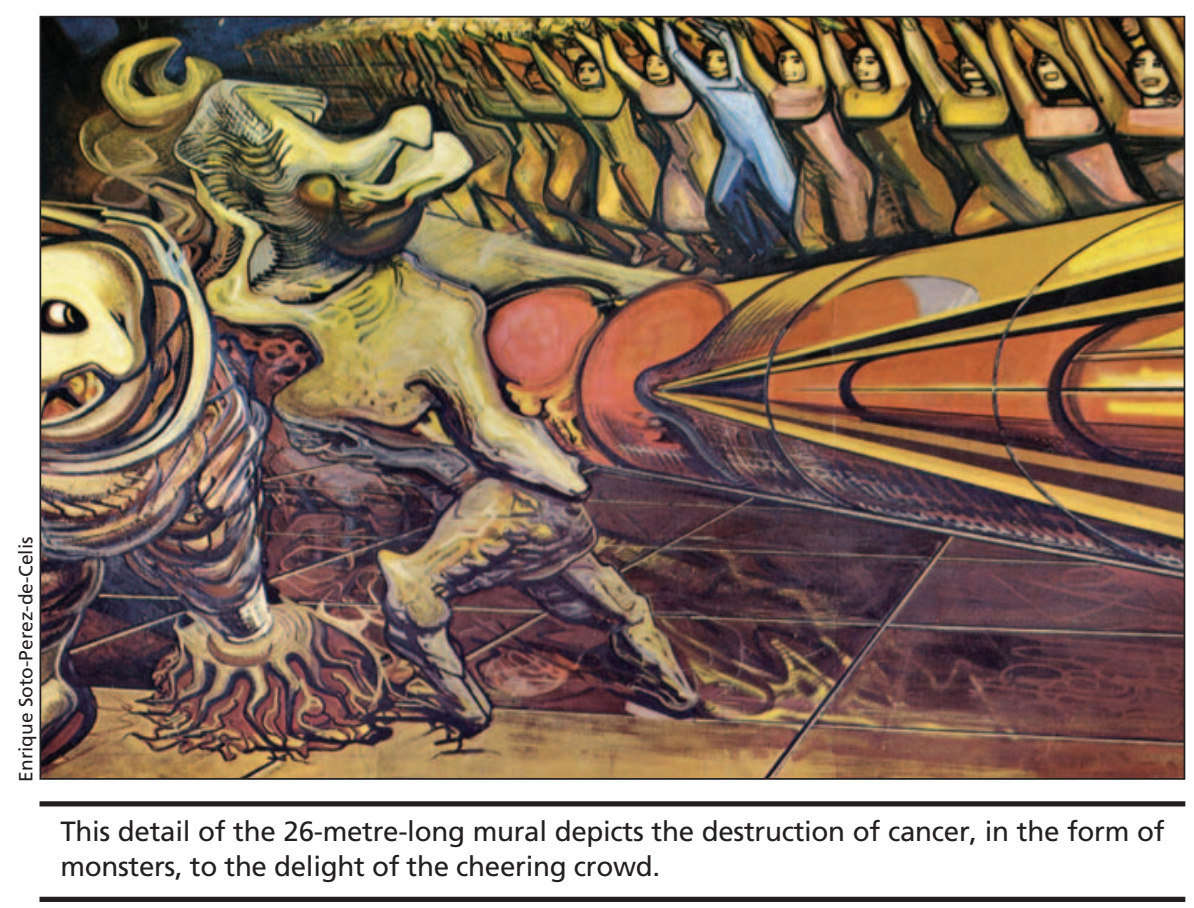

This detail of the 26-metre-long mural depicts the destruction of cancer, in the form of monsters, to the delight of the cheering crowd.

can bring to those in need. It is important to mention that most of the characters in the mural, including the doctors, are dark-skinned Mexicans. The muralist

\section{Book review}

\section{Age is only another number}

Old Endeavour: Scientific and Humanitarian Contributions by Physicians over age 65 William C. Gibson

International Association for Humanitarian Medicine Brock Chisholm; 2007 319 pp \$30.00 ISBN 978-88-902020-1-8

$\mathrm{W}$ hen do we become old? Answering this question is rather like deciding at what point high blood pressure becomes hypertension, or sadness becomes clinical depression. Age is objective, but old age is subjective. Concepts such as frailty help to describe physical and social vulnerability, but there is no easy way to measure that combination of attitude, creativity, flexibility and openness that separates those who are elderly in spirit from those who are, as we often say, young at heart.
In Old Endeavour, Dr. William Gibson presents short biographies of over 100 physicians who continued to make significant contributions to medical science past the age of 65 . The book is a companion to his earlier book, Young Endeavour, published in 1958. Gibson is associated with the Faculty of Medicine at the University of British Columbia, where he contributed to the development of the Department of the History of Medicine and Science. That he completed this book at age 93 shows that important work can be done well into what we think of as old age.

The individual biographies, each fairly brief, include well-known figures such as William Harvey, Oliver Wendell Holmes, Harvey Cushing and William Osler, as well as a number of lesser-known personalities. Accomplishments in the professional sphere movement, deeply influenced by the nationalistic politics that followed the Revolution, praised the importance of the indigenous Mexican people in the new world order.'

Siqueiros' fresco at the National Medical Center in Mexico City is a testament to the power of oncology and an expression of admiration for the happiness and prosperity that medical science can bring to the people.

\section{Enrique Soto-Perez-de-Celis MD Laboratorio de Biofísica Cardiaca Instituto de Fisiología \\ Benemérita Universidad Autónoma de Puebla \\ Puebla, Mexico}

\section{REFERENCES}

1. Instituto Méxicano del Seguro Social. Historia en los muros: Cinco muralistas y la seguridad social méxicana. Mexico: Secretaría General IMSS; 1977.

2. Iturbe S. Mural de José Chávez Morado en el Centro Médico Nacional Siglo XXI. Revista Médica IMSS 2002;40(1):85-8.

3. De Orellana M, ed. Arte y arquitectura del Instituto Méxicano del Seguro Social. Mexico City, Mexico: Artes de México, IMSS; 2006 are supplemented with personal information, quotations and anecdotes. It is unexpected, and gratifying, to see so many women represented, especially when one considers that becoming a physician at all was an impressive accomplishment for a woman born in the 19th- or early 20th-century. Readers may also be pleasantly surprised to discover that certain widely recognized names in the Canadian medical community are (or at least were at the time of publication) still alive and actively contributing to medical knowledge in some capacity.

In the introduction, Gibson highlights the "wasted intellectual talent due to enforced retirement." He points out that age 65 was arbitrarily chosen as the age for retirement in the 1880s, when the average lifespan was shorter. Now, the average life expectancy is hovering around 80 , and the declining 